\title{
Três espécies novas de Lestrimelitta Friese (Hymenoptera, Apidae) da Costa Rica, Panamá e Guiana Francesa ${ }^{1}$
}

\author{
Favízia Freitas de Oliveira² \& Paola Marchi
}

\begin{abstract}
${ }^{1}$ Contribuição número 1469 do Departamento de Zoologia da Universidade Federal do Paraná.
${ }^{2}$ Laboratório de Abelhas, Departamento de Ecologia Geral, Instituto de Biociências, Universidade de São Paulo, Rua do Matão, Travessa 14, No 321, Cidade Universitária, 05508-900 São Paulo-SP. favos@bol.com.br

${ }^{3}$ Departamento de Zoologia, Universidade Federal do Paraná, Caixa Postal 19020, 81531-990 Curitiba-PR, Brasil.paola@ufpr.br Bolsista CNPq.
\end{abstract}

\begin{abstract}
Three new species of Lestrimelitta Friese (Hymenoptera, Apidae) from Costa Rica, Panama and French Guiana. Three new species of bees of the genus Lestrimelitta are described: L. danuncia sp. nov. (from Costa Rica and Panama), L. mourei sp. nov. (from Costa Rica) and L. glaberrima sp. nov. (from French Guiana). All of these new species were previously identified as Lestrimelitta limao Smith.
\end{abstract}

KEYwORDs. Apidae; Lestrimelitta; neotropical stingless bees; taxonomy.

Resumo. Três espécies novas de Lestrimelitta Friese (Hymenoptera, Apidae) da Costa Rica, Panamá e Guiana Francesa. Três espécies novas de abelhas do gênero Lestrimelitta são descritas: L. danuncia sp. nov. (da Costa Rica e Panamá), $L$. mourei sp. nov. (da Costa Rica) e L. glaberrima sp. nov. (da Guiana Francesa). Todas essas espécies foram identificadas anteriormente como Lestrimelitta limao Smith.

Palavras-Chave. "Abelhas sem ferrão" neotropicais; Apidae; Lestrimelitta; taxonomia.

A última revisão taxonômica do gênero Lestrimelitta foi feita por Schwarz (1948), que reconheceu apenas duas espécies: L. ehrhardti Friese, 1931 (do sudeste brasileiro) e $L$. limao (Smith,1863) (que se estenderia desde o México até o sul do Brasil, Paraguai e norte da Argentina). Posteriormente, Roubik (1980) descreveu L. guyanensis (da Guiana Francesa) e Camargo \& Moure (1989) descreveram duas outras espécies da região amazônica, L. monodonta (Roraima, Brasil) e $L$. glabrata (Amazonas e Roraima, Brasil). Mais recentemente, Ayala (1999) descreveu duas outras espécies do México ( $L$. chamelensis e L. niitkib) e, com base no estudo do espécimetipo de $L$. limao, concluiu que nenhuma das formas encontradas na América Central e México correspondem à L.limao, a qual possui o espiráculo propodeal ovalado, tendo sido descrita do Brasil.

Camargo \& Moure (1989) apresentaram uma chave de identificação para operárias das espécies conhecidas até aquela data ressaltando, porém, que L. limao sensu Schwarz (1948) apresenta uma grande variação de formas e combinações de caracteres, o que indicaria um repositório de espécies distintas. Este fato foi confirmado por Oliveira (2002) que reconheceu grandes diferenças no comprimento do esporão mesotibial e na pilosidade entre as espécies deste gênero, incluindo as formas reconhecidas no complexo "limao", as quais justificam o reconhecimento de espécies distintas, algumas delas simpátricas.

No presente trabalho são descritas três espécies novas de Lestrimelitta do complexo "limao": L. danuncia sp. nov. (Costa Rica e Panamá), L. mourei sp. nov. (Costa Rica) e L. glaberrima sp. nov. (Guiana Francesa).
As abreviações utilizadas correspondem a: $\mathrm{DP}=$ diâmetro do ponto; $\mathrm{DE}=$ diâmetro de escapo; $\mathrm{T}=$ tergo. As mensurações (valores aproximados), quando não acompanhadas da unidade, são dadas em milímetros, e as larguras e/ou diâmetros, referem-se à largura ou diâmetro máximos. As medidas do comprimento das asas anteriores foram realizadas a partir do esclerito costal. A caracterização do esporão mesotibial, quanto ao seu comprimento, é a mesma utilizada por Oliveira (2002).

Os acrônimos utilizados são os seguintes: DZUP, Coleção de Entomologia Pe. J. S. Moure, Departamento de Zoologia da Universidade Federal do Paraná, Curitiba; SEMK, Snow Entomological Museum, University of Kansas, Lawrence.

\section{Lestrimelitta danuncia sp. nov.}

Lestrimelitta limao; Schwarz, 1948: 183. (partim)

Diagnose. Lóbulos pronotais sem cerdas eretas longas; cerdas eretas no centro e laterais do bordo anterior do mesoscuto, as das laterais duas vezes mais longas que as do centro $(0,20)$; escutelo cerdoso, cerdas do disco eretas porém mais curtas, finas e esparsas que no bordo posterior $(0,15: 0,30)$; pilosidade ao redor do espiráculo propodeal não tomentosa; esporão mesotibial normal (Fig. 1); cerdas relativamente longas próximo à extremidade apical do bordo anterior dos fêmures posteriores $(0,12)$; espiráculo propodeal alongado.

Holótipo operária. Cor do tegumento. Predominantemente castanho-enegrecido, exceto pelas seguintes partes: faixa estreita amarelada subapical no clípeo; face ventral do escapo 
e ápice do flagelo castanho-amarelados; mancha amarelada próxima à base das mandíbulas; pernas e tégulas castanhoclaras; escutelo com duas manchas ovais castanho-claras nas laterais do terço anterior; mancha amarelada próxima ao espiráculo propodeal; primeiro tergo um pouco mais claros que os demais.

Pilosidade. Na cabeça, cerdas curtíssimas, finas e semidecumbentes, algumas um pouco mais longas no vértice, atrás dos ocelos, incluindo a margem posterior da cabeça, de no máximo 0,09; algumas cerdas conspícuas, eretas, finas e amareladas de aproximadamente 0,05 , entre os ocelos e no ápice do escapo. Lóbulos pronotais sem cerdas eretas longas, apenas com cerdas curtíssimas, bastante finas, esparsas e decumbentes. No mesoscuto, cerdas eretas e acastanhadas no bordo anterior, as do centro mais curtas (aproximadamente 0,10 ) e as das laterais mais longas e espessas (em torno de 0,20 ); nos bordos laterais cerdas bastante curtas; pilosidade do disco do mesoscuto bastante fina, curta e densa. No escutelo, cerdas eretas relativamente curtas, finas e esparsas no disco (aproximadamente 0,15 ), e mais espessas e longas no bordo posterior (em torno de 0,30 ). Laterais do mesepisternos com cerdas muito curtas, semi-decumbentes, porém um pouco mais longas e esparsas que as da cabeça; a parte ventral com cerdas relativamente finas, longas e densas, as mais longas em torno de 0,19. Pêlos simples, bastante finos, curtos e esparsos nos flancos do propódeo (não tomentosos). Fêmures posteriores com cerdas castanho-amareladas mais espessas, densas e longas $(0,12)$ próximo da extremidade apical do bordo anterior; tíbias posteriores com cerdas castanho-enegrecidas, esbranquiçadas no terço apical, as mais longas com aproximadamente 0,28 no bordo posterior e metade deste comprimento no bordo anterior. Cerdas curtíssimas em T2 e $\mathrm{T} 3$, mais longas a partir de T4 $(0,09: 0,14: 0,16)$, mais longas e densas nas laterais dos tergos, a partir de T3 $(0,11: 0,15: 0,17: 0,20)$.

Pontuação. Tegumento liso e brilhante, com pontuação pilígera fina e densa na fronte e mesoscuto (1 a 2 DP), e mais esparsa no mesepisterno (3 a 5 DP).

Forma e proporções. Comprimento total $(5,10)$; comprimento da asa anterior $(4,50)$; cabeça mais larga do que longa $(2,25: 1,78)$; olhos levemente convergentes em cima $(1,49: 1,46)$; olhos mais longos que sua largura máxima $(1,27: 0,55)$; largura máxima dos olhos pouco menor que as genas $(0,55: 0,59)$; clípeo 3,5 vezes mais largo que longo $(1,33: 0,38) ; 1^{\circ}$ flagelômero duas vezes mais longo que o $2^{\circ}$ $(0,17: 0,09)$, porém iguais na largura $(0,16: 0,16)$; distância interalveolar um pouco maior que o comprimento do pedicelo $(0,20: 0,19)$; distância entre os ocelos laterais duas vezes o diâmetro do ocelo médio $(0,36: 0,18)$; área malar (largura mínima) um pouco mais curta que $1 \mathrm{DE}(0,14: 0,15)$; basitarsos médios três vezes mais longos que largos $(0,62: 0,17)$; basitarsos posteriores duas vezes mais longos que largos $(0,86: 0,35)$; basitarsos posteriores duas vezes mais largos que os médios
$(0,35: 0,17)$; tíbias médias três vezes mais longas que sua largura máxima (1,08:0,38); tíbias posteriores 3,5 vezes mais longas que sua largura máxima $(1,66: 0,46)$; esporão mesotibial comprido (Fig. 1), equivalendo a um terço do comprimento do basitarso médio; espiráculo propodeal alongado, cinco vezes mais longo que largo.

Macho desconhecido.

Material-tipo. Holótipo e 7 parátipos (operárias) da Costa Rica (Turrialba, 1.II.1965, R.L. Dressler col.) e 1 parátipo operária do Panamá (Panama Prov., Carti Rd., nr. El Chepo, III.1983, D. Yanager col.) (DZUP); 2 parátipos operárias da Costa Rica (Turrialba, 1.II.1965, R.L. Dressler col.) e 3 parátipos operárias do Panamá (2 [Panamá Prov., Carti Rd., El Chepo, III.1983, D. Yanager col.] e 1 [Old Panamá, 20.V.1945, C.D. Michener col.]) (SEMK).

Comentários. Espécie bastante semelhante a $L$. chamelensis Ayala, 1999 e L. niitkib Ayala, 1999 pelas cerdas do metassoma, diferindo destas, entretanto, pelo comprimento do esporão mesotibial, comprido em $L$. danuncia sp. nov. e reduzido tanto em $L$. chamelensis quanto em $L$. niitkib. A pilosidade dos flancos do propódeo bastante fina e esparsa tanto em $L$. danuncia sp. nov. quanto em $L$. niitkib, enquanto em $L$. chamelensis mais longa e densa, porém não tomentosa. Em L. chamelensis faltam as cerdas eretas longas no bordo anterior do mesoscuto; em L. danuncia sp. nov. o terço anterior do escutelo revestido por cerdas eretas pouco longas (algumas alcançando 0,07), enquanto em $L$. chamelensis por cerdas curtíssimas, finas e decumbentes. Lestrimelitta niitkib difere facilmente de L. danuncia $\mathbf{s p . ~ n o v . ~ p e l o s ~ s e g u i n t e s ~ c a r a c t e r e s : ~}$ cerdas do bordo anterior do mesoscuto mais densas e subiguais em comprimento em todo o bordo; cerdas dos mesepisternos mais longas; pilosidade dos lóbulos pronotais mais densa e comprida, com algumas cerdas eretas mais longas $(0,03)$ e espessas; pêlos plumosos facilmente visíveis no bordo posterior dos lóbulos pronotais; pilosidade do mesoscuto e escutelo muito mais comprida, as cerdas mais espessas.

Etimologia. O nome desta espécie, aposto, é uma homenagem à Dra. Danúncia Urban, professora do Departamento de Zoologia da Universidade Federal do Paraná.

\section{Lestrimelitta mourei sp. nov.}

Lestrimelitta limao; Schwarz, 1948: 183. (partim)

Diagnose. Algumas cerdas longas $(0,10)$ na margem inferior dos lóbulos pronotais; cerdas do bordo anterior do mesoscuto densas e compridas em todo o bordo (015), um pouco mais compridas no centro $(0,19)$; escutelo com cerdas curtas e esparsas no disco $(0,07)$, semi-decumbentes, e longas e densas no bordo posterior (entre 0,25 e 0,30 ); pilosidade fina porém não tomentosa ao redor do espiráculo propodeal; espiráculo propodeal alongado; esporão mesotibial reduzido (Fig. 2).

Holótipo operária. Cor do tegumento. Predominantemente acastanhado, castanho-enegrecido no mesoscuto, escutelo e 
face; castanho mais claro nas mandíbulas, genas, lóbulos pronotais, mesepisternos, propódeo e pernas; faixa estreita amarelada subapical no clípeo e na face ventral dos escapos; $\mathrm{T} 1$ e T2 um pouco mais claros que os demais tergos.

Pilosidade. Cerdas eretas no vértice, as mais longas com 0,12 (um pouco mais curtas que $1 \mathrm{DE}$ ), e mais curtas ao longo da parte posterior da cabeça. Lóbulos pronotais com algumas cerdas relativamente longas $(0,10)$ apenas na margem inferior, na face superior curtíssimas, finas e esparsas; mesoscuto com cerdas eretas castanhas no bordo anterior, as da porção central um pouco mais longas que as das laterais $(0,19: 0,15)$, no disco a pilosidade fina, curtíssima e relativamente densa. Bordo posterior do escutelo com cerdas longas e espessas, variando entre 0,25 e 0,30 , um pouco encurvadas para cima; no disco algumas cerdas muito curtas e esparsas $(0,07)$, semidecumbentes, algumas no bordo anterior um pouco mais longas $(0,11)$. Cerdas finas, curtíssimas e esparsas nas laterais dos mesepisternos; a parte ventral com cerdas finas, semidecumbentes, relativamente compridas e densas, algumas eretas mais longas em torno de 0,10 . Pêlos finos, simples, curtos e esparsos nos flancos do propódeo, não tomentosos; fêmures posteriores com cerdas enegrecidas, espessas e curtas $(0,07)$ ao longo da face dorsal; tíbias posteriores com cerdas espessas, castanhas, esbranquiçadas no terço apical, com cerca de 0,32 no bordo posterior e amais curtas e finas, com aproximadamente 0,12 no bordo anterior. Cerdas curtíssimas a partir das laterais de T2, aumentando em densidade, comprimento e espessura em direção ao ápice (T2: 0,04; T3: 0,05; T4: 0,07; T5: 0,09; T6: 0,21); e na face dorsal, curtíssimas e esparsas de T2 a T4 $(0,03)$, um pouco mais compridas em T5 $(0,07)$ e em T6, cerdas compridas, densas e espessas $(0,21)$.

Pontuação. Pontuação pilígera fina, mais densa na fronte e mesoscuto (variando entre 0,5 e $1 \mathrm{DP}$ ), mais esparsas no clípeo e mesepisterno (2 a 3 DP).

Forma e proporções. Comprimento total aproximado $(5,40)$; comprimento da asa anterior $(4,80)$; cabeça mais larga do que longa $(2,16: 1,69:)$; olhos divergentes ventralmente $(1,45: 1,51)$; olhos mais longos que sua largura máxima $(1,18: 0,55)$; largura máxima dos olhos pouco menor que as genas $(0,55: 0,60)$; clípeo três vezes mais largo que longo $(1,22: 0,38) ; 1^{\circ}$ flagelômero duas vezes mais longo que o $2^{\circ}(0,17: 0,09)$, mas praticamente iguais na largura $(0,16: 0,16)$; distância interalveolar maior que o comprimento do pedicelo $(0,21: 0,16)$; distância entre os ocelos laterais duas vezes o diâmetro do ocelo médio $(0,35: 0,17)$; área malar (distância mínima) pouco menor que $1 \mathrm{DE}(0,13: 0,14)$; basitarsos médios quatro vezes mais longos que largos $(0,77: 0,18)$; basitarsos posteriores duas vezes mais longos que largos $(0,74: 0,30)$; basitarsos posteriores duas vezes mais largos que os médios $(0,30: 0,18)$; tíbias médias três vezes mais longas que sua largura máxima $(1,13: 0,41)$; esporão mesotibial reduzido $(0,08$; Fig. 2$)$; tíbias posteriores três vezes mais longas que sua largura máxima $(1,54: 0,53)$; espiráculo propodeal alongado, quatro vezes mais longo que largo $(0,30: 0,08)$.
Macho desconhecido.

Material-tipo. Holótipo e um parátipo (operárias) da Costa Rica (San Jose Prov., 15.VI.1963, C.D \& D.R. Michener col.) (SEMK); um parátipo operária da Costa Rica (San Jose Prov., 15.VI.1963, C.D \& D.R. Michener col.) (DZUP).

Comentários. Espécie bastante semelhante a $L$. chamelensis e L. niitkib pelas cerdas do metassoma e pelo esporão mesotibial reduzido. Difere de L. niitkib pelas cerdas do bordo anterior do mesoscuto mais compridas e as cerdas dos mesepisternos mais curtas em L. mourei sp. nov., e as cerdas da metade anterior do escutelo muito mais compridas e densas em L. niitkib. Difere-se facilmente de $L$. chamelensis pela presença de cerdas no bordo anterior do mesoscuto, pela pilosidade mais densa e comprida na face dorsal do mesoscuto e a pilosidade dos flancos do propódeo mais curta e esparsa.

Etimologia. O nome desta espécie é uma homenagem ao Dr. Jesus Santiago Moure, professor do Departamento de Zoologia da Universidade Federal do Paraná.

\section{Lestrimelitta glaberrima sp. nov.}

Diagnose. Sem cerdas eretas nos lóbulos pronotais (apenas cerdas curtíssimas, esparsas e decumbentes); poucas cerdas relativamente curtas nas laterais do bordo anterior do mesoscuto (em torno de três, com 0,06 ); face dorsal do escutelo com cerdas curtíssimas, quase imperceptíveis, no bordo posterior, poucas cerdas eretas (em torno de 12), relativamente curtas e esparsas $(0,09)$; esporão mesotibial normal (Fig. 3); pilosidade dos flancos do propódeo muito curta, fina e esparsa; espiráculo propodeal alongado.

Holótipo operária. Cor do tegumento. Predominantemente castanho-enegrecido, faixa estreita subapical ao clípeo amarelada; mandíbulas, pronoto e pernas castanho-claros.

Pilosidade. Poucas cerdas muito curtas no vértice, algumas um pouco mais compridas $(0,06)$ entre os ocelos e na margem posterior da cabeça. Lóbulos pronotais sem cerdas eretas compridas, com apenas cerdas curtíssimas, finas, esparsas e decumbentes. Poucas cerdas curtas e finas nas laterais do bordos anterior do mesoscuto (em torno de três, com 0,06); nas laterais, próximo às axilas, um pouco mais longas, espessas e densas $(0,09)$; pilosidade do disco do mesoscuto decumbente, curtíssima, fina e esparsa, quase imperceptível. Cerdas do disco do escutelo curtíssimas, finas, muito esparsas e semi-decumbentes; algumas cerdas eretas (em torno de 12) relativamente curtas no bordo posterior do escutelo $(0,09)$, muito esparsas. Laterais do mesepisterno com cerdas finas, curtíssimas e esparsas, quase imperceptíveis; na parte ventral, mais longas e densas, semi-decumbentes, algumas semi-eretas em torno de 0,10. Flancos do propódeo aparentemente glabros, com cerdas curtíssimas e esparsas. Tíbias médias com cerdas amareladas curtas e esparsas no bordo posterior, com até 0,10 , mais longas próximo ao ápice; fêmures posteriores com cerdas 

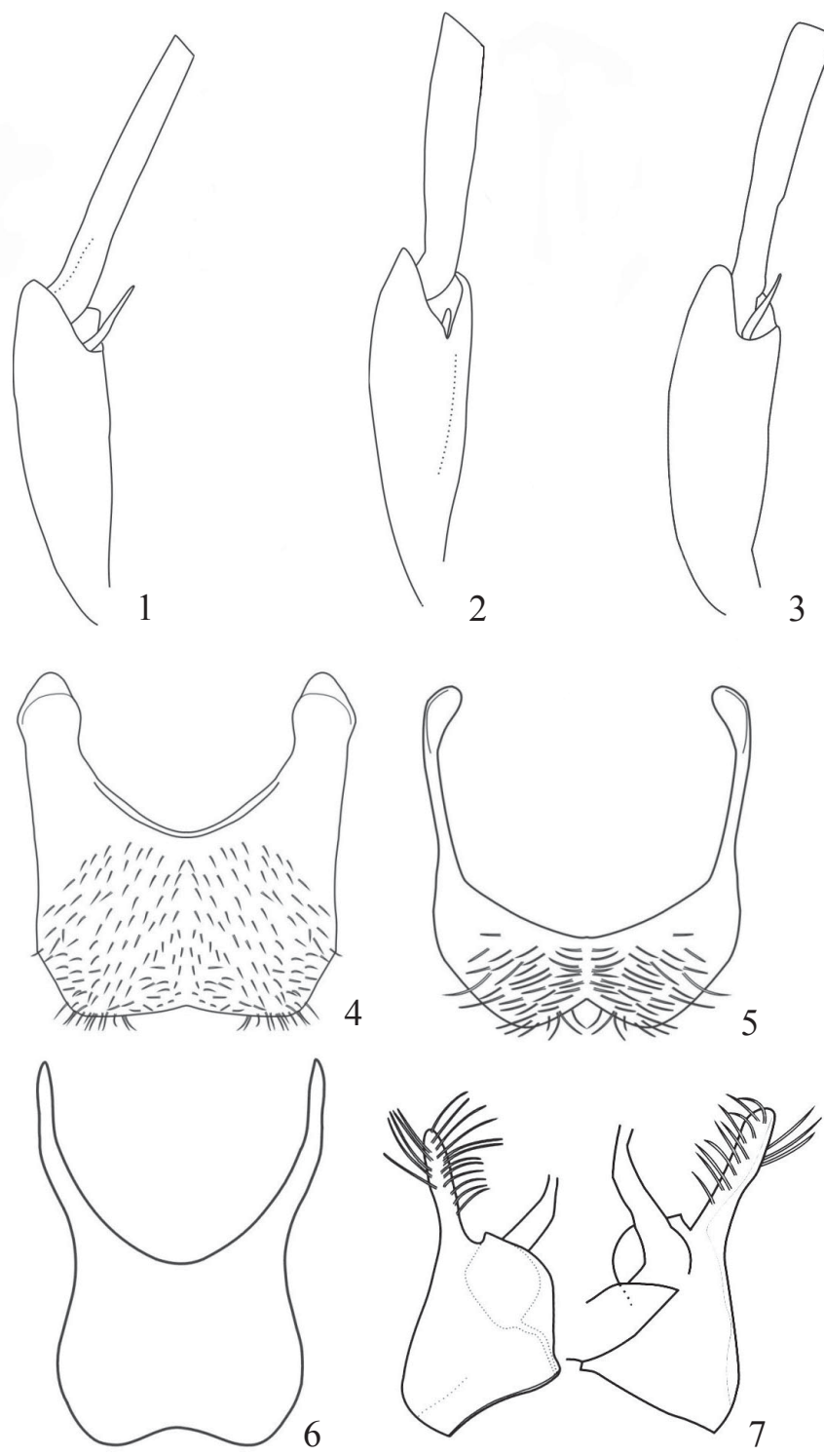

Figs. 1-7. 1-3, Tíbia média evidenciando o esporão: 1, L. danuncia sp. nov.; 2, L. mourei sp. nov.; 3, L. glaberrima sp. nov.. 4-7, Alótipo macho de $L$. glaberrima sp. nov.: $4,5^{\circ}$ esterno; $5,6^{\circ}$ esterno; $6,7^{\circ}$ esterno; 7, cápsula genital em vista dorsal e ventral.

em torno de 0,09 no terço apical da face dorsal; tíbias posteriores com cerdas castanho-enegrecidas, em torno de 0,26 no bordo posterior e cerca de metade deste comprimento no bordo anterior. Metassoma com cerdas castanhas muito curtas e esparsas de T2 a T3, um pouco mais compridas nas laterais; em T4 cerdas em torno de 0,07 nas laterais, próximas ao bordo posterior; T5 com cerdas de 0,10 nas laterais; T6 cerdoso, as cerdas longas, espessas e densas, em torno de 0,18 .

Pontuação. superfície do tegumento lisa e brilhante com pontuação pilígera fina e bastante densa na fronte (0,5 DP), mais esparsa no clípeo e mesoscuto (1 DP); no mesepisterno, pontos maiores, variando entre 1 e $2 \mathrm{DP}$.
Forma e proporções. Comprimento total aproximado $(5,0)$; comprimento da asa anterior $(4,30)$; cabeça mais larga do que longa $(2,15: 1,56)$; olhos levemente divergentes inferiormente $(1,33: 1,36)$; olhos mais longos que sua largura máxima $(1,27: 0,65)$; largura máxima dos olhos maior que as genas $(0,65: 0,58)$; clípeo 3,5 vezes mais largo que longo (1,33:0,38); $1^{\circ}$ flagelômero 1,5 vezes mais longo que o $2^{\circ}(0,16: 0,10)$, mas praticamente iguais na largura $(0,14: 0,14)$; distância interalveolar pouco maior que o comprimento do pedicelo $(0,19: 0,18)$; distância entre os ocelos laterais duas vezes o diâmetro do ocelo médio $(0,29: 0,15)$; área malar (distância mínima) pouco menor que $1 \mathrm{DE}(0,13: 0,14)$; basitarsos médios em torno de quatro vezes mais longos que largos $(0,79: 0,18)$; basitarsos posteriores cerca de três vezes mais longos que largos $(0,79: 0,29)$; basitarsos posteriores duas vezes mais largos que os médios $(0,29: 0,18)$; tíbias médias três vezes mais longas que sua largura máxima $(1,03: 0,36)$; tíbias posteriores 3,5 vezes mais longas que sua largura máxima $(1,49: 0,43)$; esporão mesotibial normal, em torno de 0,22 (um terço do comprimento do basitarso médio; Fig. 3); espiráculo propodeal estreito e alongado, quatro vezes mais longo que largo $(0,31: 0,08)$.

Alótipo macho (Figs. 4 a 7). Semelhante à operária, diferindo desta pelos seguintes caracteres: Cor do tegumento. Tratandose de um indivíduo jovem, o tegumento é mais claro, predominantemente acastanhado; labro, mandíbulas, pronoto e pernas amarelados.

Pilosidade. Ausência de cerdas eretas compridas nas laterais do bordo anterior, próximo às axilas do mesoscuto e no bordo posterior do escutelo; tíbias médias aparentemente glabras, exceto próximo ao ápice, com cerdas longas e encurvadas em torno de 0,14 ; pouquíssimas cerdas compridas no ápice dos fêmures posteriores; tíbias posteriores com cerdas eretas e compridas em torno de 013 , apenas no $1 / 4$ apical do bordo anterior; as do bordo posterior muito compridas $(0,36)$ e esbranquiçadas nos $T$ ! apicais, na face dorsal, algumas cerdas curtas $(0,17)$ e mais longas, espessas e encurvadas próximo ao ápice $(0,27)$, algumas com ramificações curtas no terço apical. Metassoma com cerdas curtíssimas, aparentemente glabro, com exceção de cerdas muito longas nas laterais de T5 $(0,19)$, T6 $(0,42)$; no bordo posterior de T7, cerdas em torno de 0,15 na porção central e 0,48 nas laterais; a metade apical das cerdas esbranquiçada em T6 e T7.

Forma e proporções. Comprimento total aproximado 3,50; comprimento das asas anteriores 3,70 ; cabeça mais larga do que longa $(1,92: 1,44)$; olhos convergentes inferiormente $(1,14: 0,98)$; olhos mais longos que sua largura máxima $(1,25: 0,62)$; largura máxima dos olhos maior que as genas $(0,62: 0,36)$; clípeo 2,5 vezes mais largo que longo $(1,04: 0,41)$; comprimento máximo do $1^{\circ}$ flagelômero igual ao do $2^{\circ}(0,15: 0,15)$, e também iguais na largura $(0,16: 0,16)$; distância interalveolar pouco maior que o comprimento do pedicelo $(0,17: 0,15)$; distância entre os ocelos laterais menor que o diâmetro do ocelo médio $(0,12: 0,17)$; área malar (largura mínima) praticamente 
a metade do diâmetro do escapo $(0,08: 0,16)$; basitarsos médios cerca de sete vezes mais longos que largos $(0,76: 0,11)$; basitarsos posteriores quatro vezes mais longos que largos $(0,76: 0,19)$; basitarsos posteriores quase duas vezes mais largos que os médios $(0,19: 0,11)$; tíbias médias 2,5 vezes mais longas que sua largura máxima (1,03:0,39); tíbias posteriores em torno de três vezes mais longas que sua largura máxima $(1,30: 0,46)$; esporão mesotibial reduzido.

Material-tipo. Holótipo (operária), alótipo (macho) e um parátipo operária da Guiana Francesa (Kourou beach, 15.V.1977, D. Roubik col.) (SEMK); um parátipo operária da Guiana Francesa (Kourou beach, 15.V.1977, D. Roubik col.) (DZUP).

Comentários. Semelhante a L. glabrata Camargo \& Moure, 1989, diferindo desta pelos seguintes caracteres: em $L$. glabrata, as cerdas da metade posterior do escutelo são muito compridas e densas $(0,40)$; tíbias médias com cerdas longas, espessas e densas $(0,23)$ no bordo posterior e na face dorsal, as cerdas mais longas e densas em torno de 0,13 , próximo ao ápice; tíbias posteriores com cerdas mais longas e densas, especialmente as do bordo anterior, o $1 / 4$ basal com cerdas longas e relativamente densas $(0,17)$; metassoma inteiramente cerdoso, as cerdas relativamente compridas e densas $(0,20)$. O macho de $L$. glabrata difere facilmente do macho de $L$. glaberrima pelas cerdas do bordo posterior do escutelo muito compridas $(0,40)$, densas, encurvadas e com ramificações curtas no ápice; bordo posterior das tíbias médias com cerdas muito compridas (em torno de 0,50), espessas, densas, esbranquiçadas no ápice e ramificadas no terço apical; as do quarto apical das tíbias médias, um pouco mais curtas $(0,20) \mathrm{e}$ menos densas; fêmures posteriores com cerdas muito compridas e densas no ápice; as tíbias posteriores inteiramente cerdosas, cerdas compridas, densas e com ramificações abertas, com aspecto espatulado, em torno de 0,25 na face dorsal e mais densas e compridas no bordo posterior $(0,50)$, esbranquiçadas no ápice; o metassoma inteiramente cerdoso, as cerdas muito compridas e densas (com aproximadamente 0,27), esbranquiçadas no ápice e algumas com ramificações compactas próximas no terço apical; apresenta o esporão mesotibial comprido.

L. guyanensis Roubik, 1980 difere facilmente de $L$. glaberrima pelas presença de pilosidade curta e densa e algumas cerdas eretas compridas na parte inferior dos lóbulos pronotais; as cerdas das laterais no bordo anterior do mesoscuto muito mais compridas e densas $(0,30)$; cerdas do bordo posterior do escutelo muito compridas e densas $(0,60)$; cerdas do bordo posterior das tíbias médias mais densas e compridas $(0,20)$; metassoma com cerdas muito longas nas laterais (em torno de 0,20 ).

No alótipo macho (Fig. 7) falta a ponta das valvas.

Etimologia. Do latim glabro (sem pêlos) + érrimo (sufixo utilizado para formar o superlativo absoluto sintético dos adjetivos), refere-se à sua aparência bastante glabra, se comparada com as outras espécies de Lestrimelitta, especialmente com L. glabrata.
Chave para as operárias das espécies de Lestrimelitta que ocorrem do México ao norte da América do Sul

1. Cabeça e mesepisternos praticamente glabros; geralmente sem cerdas eretas no bordo anterior do mesoscuto (quando presentes curtas, bastante finas, em número de 1 a 3 e apenas nas laterais) ................... 2

Cabeça com cerdas eretas longas e densas na margem posterior, atrás dos ocelos; pilosidade dos mesepisternos variável; mesoscuto com cerdas eretas em todo o bordo anterior

2(1). Abelhas menores (comprimento em torno de 5; largura máxima da cabeça em torno de 2,15); T2 a T5 com cerdas muito curtas e esparsas em todo o tergo; cerdas das tíbias médias relativamente curtas e esparsas, na face dorsal e no bordo posterior (no máximo 0,10 no bordo posterior); cerdas do escutelo muito curtas, esparsas e pouco numerosas, ou numerosas porém moderadamente compridas ............................................ 3

Abelhas maiores (comprimento entre 6,96 e 7,35; largura máxima da cabeça em torno de 2,50); sem cerdas nas laterais posteriores do mesoscuto (próximo às axilas); escutelo com cerdas muito longas, espessas e densas (entre 0,40 a 0,60 ) a partir da metade posterior; cerdas das tíbias médias relativamente longas na face dorsal e no bordo posterior (no bordo posterior em torno de 0,20); T2 a T5 com cerdas longas em toda a superfície do tergo ou apenas nas laterais .. 4

3(2). Pilosidade dos flancos do propódeo relativamente longa e densa, porém fina, sem aspecto tomentoso; cerdas do escutelo moderadamente longas; esporão mesotibial muito reduzido. México L. chamelensis Ayala, 1999

Pilosidade dos flancos do propódeo muito fina, curta e esparsa, quase imperceptível; algumas cerdas eretas nas laterais do mesoscuto próximo às axilas; escutelo com poucas cerdas muito curtas apenas no bordo posterior (em torno de 0,09 ); esporão mesotibial longo (Fig. 3). Guiana Francesa

L. glaberrima sp. nov.

4(2). Cerdas eretas longas e numerosas nas laterais do bordo anterior do mesoscuto $(0,30)$; lóbulos pronotais com cerdas eretas longas na parte inferior e pêlos plumosos relativamente longos e densos no bordo posterior; esporão mesotibial muito reduzido; T2 a T5 com cerdas enegrecidas, espessas e longas nas laterais. Guiana Francesa

L. guyanensis Roubik, 1980

Bordo anterior do mesoscuto geralmente sem cerdas eretas, se presentes, relativamente curtas, bastante finas e pouco numerosas (entre 1 e 3); lóbulos pronotais sem cerdas eretas longas; esporão mesotibial normal T2 a T5 com cerdas compridas em 
todo o tergo. Brasil (Roraima, Amazonas e Rondônia) L. glabrata Camargo \& Moure, 1989

5(1). Mandíbulas com apenas um dente interno subapical; lóbulos pronotais com muitas cerdas eretas longas (em torno de 0,10); laterais dos mesepisternos cerdosas, as cerdas mais longas $(0,16)$ na porção anterior, abaixo dos lóbulos pronotais; flancos do propódeo com pilosidade longa e ramificada Brasil (Roraima, Amazonas, Pará e Maranhão)

L. monodonta Camargo \& Moure, 1989

Mandíbulas com dois dentes pequenos subapicais; lóbulos pronotais e laterais dos mesepisternos sem cerdas eretas longas; flancos do propódeo com pilosidade curta e fina 6

6(5). Pilosidade do mesossoma muito curta $(0,02)$, bastante fina e esparsa, sem aspecto esbranquiçado (entre 2 e 2,5 DP), nos mesepisternos e no disco do mesoscuto ainda mais curta e esparsa; cerdas das laterais do bordo anterior do mesoscuto aproximadamente duas vezes mais longas que as da porção mediana; esporão mesotibial normal (Fig. 1). Costa Rica e Panamá L. danuncia sp. nov.

Pilosidade do mesossoma curta $(0,05)$ e densa (entre 1 e 1,5 DP), conferindo aspecto esbranquiçado, especialmente no mesoscuto e na face dorsal das tíbias médias; cerdas do bordo anterior do mesoscuto subiguais em comprimento ou um pouco mais longas na porção mediana; esporão mesotibial reduzido (Fig. 2).

7(6). Cerdas relativamente longas e densas em toda a face dorsal do escutelo; lóbulos pronotais pilosos, os pêlos plumosos do bordo posterior facilmente visíveis, com algumas cerdas finas um pouco mais longas e eretas na metade inferior $(0,04)$. México

L. niitkib Ayala, 1999

Escutelo com cerdas eretas relativamente longas e densas apenas no bordo posterior (entre 0,25 e 0,30), as do disco curtas e esparsas $(0,07)$; lóbulos pronotais praticamente glabros, porém com cerdas eretas relativamente longas no bordo inferior $(0,10)$. Costa Rica L. mourei sp. nov.

Agradecimentos. À Dra. Danúncia Urban e ao Dr. Jesus Santiago Moure (Departamento de Zoologia da Universidade Federal do Paraná) pelo incentivo à publicação do presente artigo. Ao Dr. Michael S. Engel (University of Kansas, Lawrence, USA), pelo incentivo à publicação do presente artigo, doação e empréstimo do material estudado. À CAPES pela concessão da Bolsa de Doutorado à primeira autora, e ao $\mathrm{CNPq}$ pela Bolsa de Mestrado à segunda autora.

\section{REFERÊNCIAS}

Ayala, R. 1999. Revision de las abejas sin aguijon de Mexico (Hymenoptera: Apidae: Meliponini). Folia Entomologica Mexicana 106: 1-123.

Bego, L. R.; R. Zucchi \& S. Mateus. 1991. Notas sobre a estratégia alimentar (cleptobiose) de Lestrimelitta limao Smith (Hymenoptera, Apidae, Meliponinae). Naturalia 16: 119-127.

Camargo, J. M. F. \& J. S. Moure. 1989. Duas espécies novas de Lestrimelitta Friese (Meliponinae, Apidae, Hymenoptera) da região amazônica. Boletim do Museu Paraense Emilio Goeldi, Série Zoologia 5: 195-212.

Oliveira, F. F. de. 2002. The Mesotibial Spur in Stingless Bees: A New Character for the Systematics of Meliponini (Hymenoptera: Apidae). Journal of the Kansas Entomological Society 75 : 194-202.

Roubik, D. W. 1980. New species of Trigona and cleptobiotic Lestrimelitta from French Guiana (Hymenoptera: Apidae). Revista de Biologia Tropical 28: 263-269.

Schwarz, H. F. 1948. Stingless bees (Meliponidae) of the Western Hemisphere. Bulletin of the American Museum of Natural History 90: 1-546. 